\title{
A Study of Morphometric and Topographic Anatomy of Nutrient Foramen in Fibula
}

\section{ABSTRACT}

Introduction: Long bones receive its primary blood supply from the nutrient arteries. They are transmitted through oblique canals, called nutrient foramina, into its diaphysis. Knowledge of foraminal topography helps to preserve bone vascularity during surgeries.

Aim: To estimate the morphometric and topographic characteristics of diaphyseal nutrient foramina of fibula.

Materials and Methods: A descriptive osteometric and morphological assessment of 50 dry fibulae of unknown age and sex were done. The samples were obtained from the Department of Anatomy, Kanyakumari Government Medical College, Asaripallam, Tamil Nadu, India. The length of each bone was measured directly using a measuring tape. Number, location and the direction of nutrient foramina were observed and the data were presented in a tabulated format.

Results: The mean height of the fibula on the right side was $35.86 \pm 2.441 \mathrm{~cm}$, whereas on the left was $36.64 \pm 2.537 \mathrm{~cm}$. It was observed that $92 \%$ of the right and $96 \%$ of the left bones presented a single foramen. The nutrient foramina were predominately present on the posterior surface of the middle third of the shaft and were directed away from the growing end of the bone.

Conclusion: As vascularised osteocutaneous fibular graft is recommended as a useful treatment option for bone transplant surgeries, the data gathered in this study could be useful for the orthopaedic surgeons.

\section{INTRODUCTION}

Fibula is the slender lateral bone of leg, characterised by a proximal head, a twisted shaft and a distal lateral malleolus. It is not directly involved in the transmission of body weight. A little proximal to the midpoint of its posterior surface, fibular shaft is pierced by a nutrient foramen, directed distally [1]. The direction of nutrient foramen determines the growing end of the bone. The blood supply of long bone occurs through the nutrient foramen which allows passage of nutrient vessels and nerves into the diaphysis. The knowledge about the nutrient foramina is of crucial importance especially in surgical procedures like bone grafting and micro-vascular bone transfer. In adults, fibula measures $35-45 \mathrm{~cm}$ in length and $1.5-2 \mathrm{~cm}$ in width. This furnishes a strong cortical strut, which can be used for bone grafting. 'Free fibular grafts' are well suited for the reconstruction of segmental defects of long bones, which provides mechanical strength and biological stimulus for healing [2]

The nutrient artery of fibula, a branch of peroneal artery runs along the posterior aspect of its diaphysis and enters the nutrient foramen. In addition, the fibula receives a number of segmental musculo-periosteal vessels, which also emanate from the peroneal artery and mostly supply the middle third of the diaphysis. The fibula is supplied by both of its endosteal and periosteal vessels. In the absence of nutrient artery which provides the endosteal blood supply, periosteal vessels form the sole source for supplying the entire diaphysis of the long bone. Vascularised bone grafts are immediately viable, as they are placed with intact vessels. Fibular shaft can be transplanted with its nutrient vessels which can be anastomosed with the existing vessel near the recipient bone. The graft being a living bone unites with the recipient bone like an ordinary fracture fragment without complications.

The objective of present research was to study the diaphyseal nutrient foramina of dry fibula both morphometrically and topographically. Ojaswini $\mathrm{M}$ and Hemang $\mathrm{J}$ reported that, of the $90.8 \%$ nutrient foramina on the posterior surface of fibula, $75 \%$ was noticed on middle third, $9 \%$ on the distal third and $4 \%$ on proximal third of the shaft [3]. Usma R et al., studied 100 fibulae and noticed that nutrient foramina were located on the posterior surface in $62.89 \%$ and along the medial crest in $30.93 \%$ of the bone [4]. According to Vinay G and Mangalgowri SR, $87.8 \%$ of the foramina were found over the posterior surface [5]. Since, there is much ambiguity in the exact location of nutrient foramina in relation to the fibular surface and zone, an understanding of the regional distribution of nutrient foramina is necessary to avoid injury to the nutrient vessels during surgery.

\section{MATERIALS AND METHODS}

A descriptive cross-sectional study was carried out in a total of 50 (25 right and 25 left) dry adult fibulae of unknown sex and age obtained from the Department of Anatomy, Kanyakumari Government Medical College, Asaripallam, Kanyakumari District. The study was conducted in dry fibulae procured from the bodies donated for research and study purpose. An informed consent was obtained by the institution from the body donors or their authorised legal representatives at the time of donation.

Inclusion criteria: Fifty (25 right and 25 left) dry adult fibulae, irrespective of age and sex were included in the study.

Exclusion criteria: Fibulae showing notable loss of osseous material, previous signs of fracture or pathological abnormalities were excluded from the study.

\section{Study Procedure}

All the bones were observed for their length, number, location and the direction of the nutrient foramina. The total length of each bone was measured from the apex of the head of fibula to the tip of the lateral malleolus using a measuring tape [Table/Fig-1]. The position of the nutrient foramina on the fibular shaft was located and their distance from the proximal end of the bone was recorded.

The Foramen Index (FI) was calculated using Hughes formula:

$\mathrm{Fl}=(\mathrm{DNF} / \mathrm{TL}) \times 100$

DNF- Distance from the proximal end of the bone to the nutrient foramen

\section{TL- Total length of the bone}

Larger foramen was considered in bones with double nutrient foramina. 


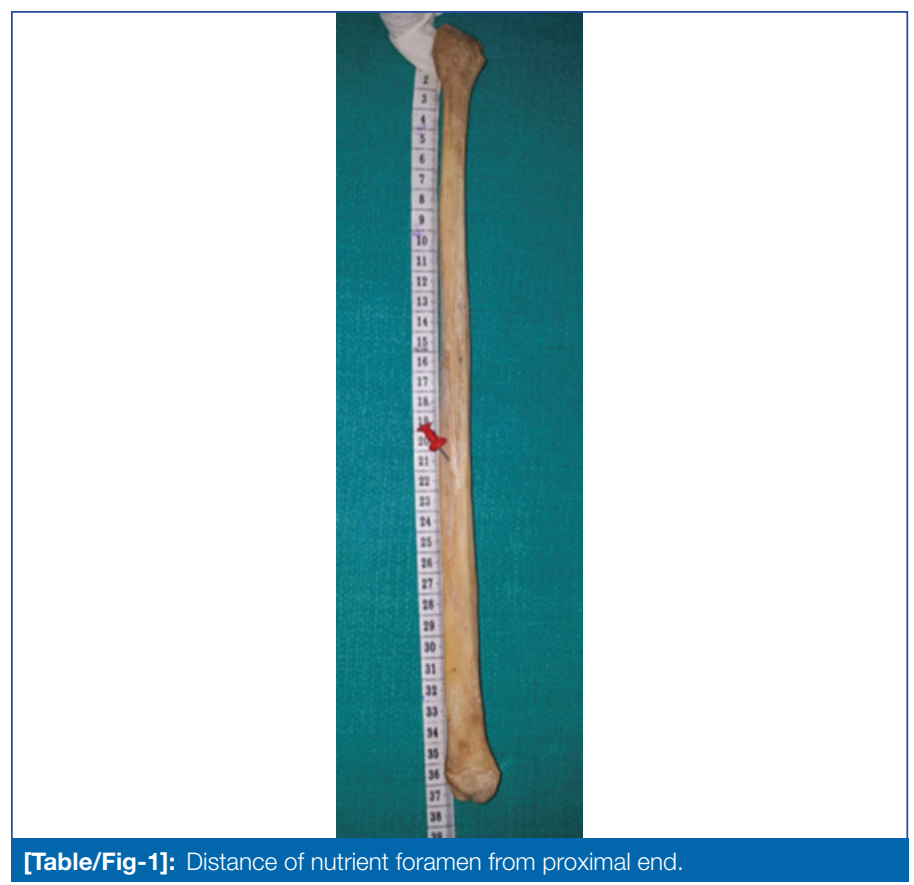

\section{STATISTICAL ANALYSIS}

Data was tabulated and statistical analysis in the form of mean and Standard Deviation (SD) was done for length and foramen indices of fibula. Simple percentage calculation was done for numeric and topographic variations of the diaphyseal nutrient foramen.

\section{RESULTS}

A total of 50 dry adult fibulae were examined for their length; number, location and direction of nutrient foramina and the following observations were made. Mean length of right fibula was $35.86 \pm 2.441 \mathrm{~cm}$ and $36.64 \pm 2.537 \mathrm{~cm}$ for the left. Mean foramen indices were $48.76 \pm 8.802$ and $44.88 \pm 7.053$ for the right and left fibula, respectively [Table/Fig-2]. Double nutrient foramina were noticed in $2(8 \%)$ of right and 1 (4\%) of the left fibula. Rest of the bones presented single nutrient foramen [Table/Fig-3]. Nutrient foramen was located on the posterior surface in $19(76 \%)$ of right and $17(68 \%)$ of left fibula. In 6 (24\%) of the right and 8 (32\%) of the left fibula foramen was located on the anteromedial surface [Table/Fig-3]. Nutrient foramen was directed away from the growing end in majority (100\% right and $96 \%$ left) of fibula, while in $4 \%$ of left fibula foramen was pointed towards the growing end of the bone [Table/Fig-3].

\begin{tabular}{|l|l|c|c|c|}
\hline \multicolumn{2}{|c|}{} & \multicolumn{3}{|c|}{ Foramen Index (FI) } \\
\cline { 3 - 5 } \multicolumn{2}{|l|}{ Variables } & $\begin{array}{c}\text { Total Length } \\
\text { (TL) (cm) }\end{array}$ & $\begin{array}{c}\text { Distance of Nutrient } \\
\text { Foramen from Proximal } \\
\text { End (DNF) (cm) }\end{array}$ & $\begin{array}{c}\text { Foramen } \\
\text { Index (FI) }\end{array}$ \\
\hline \multirow{3}{*}{$\begin{array}{l}\text { Right } \\
\text { fibula (25) }\end{array}$} & Mean \pm SD & $35.86 \pm 2.441$ & $17.58 \pm 3.95$ & $48.76 \pm 8.802$ \\
\cline { 2 - 5 } & Maximum & 40.5 & 27 & 64.06 \\
\cline { 2 - 5 } & Minimum & 31 & 11.5 & 36.32 \\
\hline \multirow{3}{*}{$\begin{array}{l}\text { Left fibula } \\
\text { (25) }\end{array}$} & Mean \pm SD & $36.64 \pm 2.537$ & $15.8 \pm 2.471$ & $44.88 \pm 7.053$ \\
\cline { 2 - 5 } & Maximum & 40.5 & 22 & 62.12 \\
\cline { 2 - 5 } & Minimum & 29 & 13.5 & 34.56 \\
\hline \multirow{2}{*}{ [Table/Fig-2]: Foramen indices. } & & & \\
\hline
\end{tabular}

\begin{tabular}{|l|l|c|c|}
\hline \multicolumn{2}{|l|}{ Variables } & $\begin{array}{c}\text { Right fibula } \\
(25)\end{array}$ & $\begin{array}{c}\text { Left fibula } \\
(25)\end{array}$ \\
\hline \multirow{3}{*}{ No. of nutrient foramen } & One & $23(92 \%)$ & $24(96 \%)$ \\
\cline { 2 - 4 } & Two & $2(8 \%)$ & $1(4 \%)$ \\
\cline { 2 - 4 } & Absent & $0(0 \%)$ & $0(0 \%)$ \\
\hline \multirow{4}{*}{ Location of nutrient foramen } & Posterior surface & $19(76 \%)$ & $17(68 \%)$ \\
\cline { 2 - 4 } & $\begin{array}{l}\text { Anteromedial } \\
\text { surface }\end{array}$ & $6(24 \%)$ & $8(32 \%)$ \\
\cline { 2 - 4 } & Lateral surface & - & - \\
\hline
\end{tabular}

\begin{tabular}{|l|l|c|c|}
\hline \multirow{2}{*}{ Direction of nutrient foramen } & $\begin{array}{l}\text { Away from the } \\
\text { growing end }\end{array}$ & $25(100 \%)$ & 24 (96\%) \\
\cline { 2 - 4 } & $\begin{array}{l}\text { Towards the } \\
\text { growing end }\end{array}$ & $0(0 \%)$ & $1(4 \%)$ \\
\hline
\end{tabular}

\section{DISCUSSION}

The fibula has been identified as the preferred choice for bone grafting procedures. Free vascularised fibular flaps are used for reconstruction of skeletal, soft tissue and growth plate defects. Fibula is an excellent vascularised graft source, because of its anatomic accessibility, independent blood supply and also because removing an intercalary segment with preservation of the proximal and distal fibular segments would have minimal effect on the gross function of lower extremity.

Length of fibula: The mean length of fibula in the present study was found to be $35.86 \pm 2.441 \mathrm{~cm}$ and $36.64 \pm 2.537 \mathrm{~cm}$ in the right and left-sides, respectively. Similar observation was reported by Kaur J and Srivasatava D, who noticed that the mean length of the fibula was $35.58 \mathrm{~cm}$, ranging between $32 \mathrm{~cm}$ and $40 \mathrm{~cm}$ [6]. They also revealed that the mean length of bone procurable for graft, sparing proximal $7 \mathrm{~cm}$ and the distal third of the bone for preserving the stability of ankle joint was $16.72 \mathrm{~cm}$. The advantage of such graft is the available length of bone that can be utilised for large bone defects requiring more than $10 \mathrm{~cm}$.

Foramen index: Zahid A et al., classified the position of nutrient foramina based on Fl. Type-1 had Fl less than 33.33, the foramen was in the proximal third of the bone. In Type-2, FI was in the range of 33.33 to 66.66 , the foramen was in the middle third and in Type-3, FI was greater than 66.66, the foramen was in the distal third of the bone. They noticed that the mean FI on the left was $47.651 \pm 7.601$ and on the right was $50.283 \pm 11.478$ [7]. McKee $\mathrm{NH}$ et al., noticed that $96 \%$ of the foramina were on the middle third of the fibula and recommended that this segment of the shaft should be considered for free vascularised fibular grafts to increase the prospect of including the endosteal blood supply [8]. In the present study, mean FI on the right side was $48.76 \pm 8.802$ and on the left was $44.88 \pm 7.053$, suggesting high vascularity in the middle third of the bone. This finding was in accordance with previous studies, ensuring that middle third of the shaft is the ideal segment for bone grafting.

Number of nutrient foramina: A single nutrient foramen $(92 \%$ in right and $96 \%$ in left fibula) appeared to be the most prevalent finding in the present study [Table/Fig-4]. Similarly double nutrient foramina were noticed in $8 \%$ of the right and $4 \%$ of the left fibula [Table/Fig-5]. This relatively small number of double nutrient foramina corroborated with the findings of Gumusburun E et al., [9]. In a study on Asian Indian subjects, Prashant KU et al., noticed that

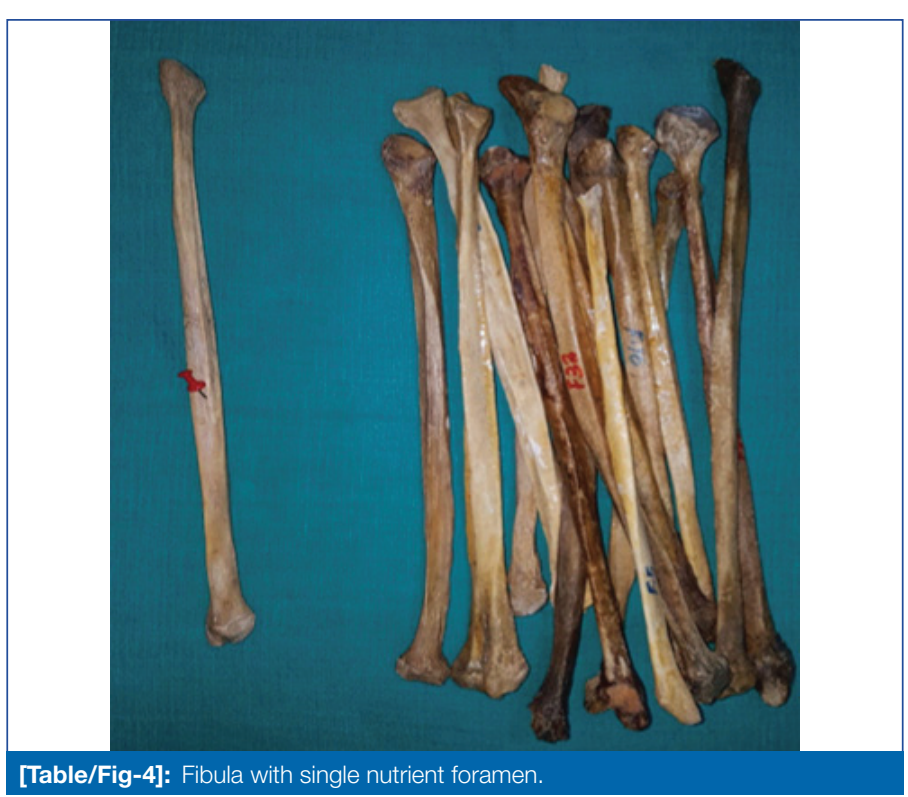


$90.2 \%$ of the fibula had single foramen and in $9.8 \%$, the foramen was absent [10]. Another study conducted in the Indian population by Sharma MD et al., in 150 dry adult fibulae, revealed absence of nutrient foramina in $6 \%$, single foramen in $86.5 \%$, double and triple foramina in $6.5 \%$ and $1 \%$, respectively [11]. The presence of nutrient foramina is primarily important for the vascularisation of the fibular shaft because, the survival of osteophytes in pathological conditions, are dependent on adequate nutrient blood flow.

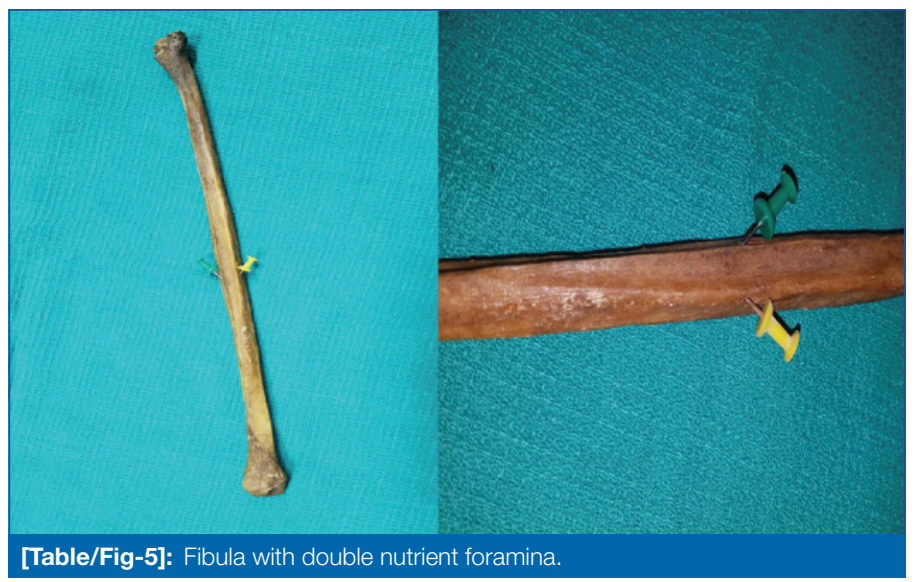

Location of nutrient foramina: Position of diaphyseal nutrient foramen in long bones follows a definite pattern. Generally, it is placed on the flexor surface of the bones (anterior aspect in upper limb bones and posterior aspect in lower limb bones). The current study identified the presence of nutrient foramina on the posterior surface in $76 \%$ of the right and $68 \%$ of the left fibula and on the anteromedial surface in $24 \%$ of the right and $32 \%$ of the left fibula. Collipal $\mathrm{E}$ et al., reported that in South American population, nutrient foramina were located on the posterior surface in $68 \%$, medial surface in $14 \%$, interosseous border in $12 \%$, lateral surface in $4 \%$ and posterior border in $2 \%$ [12]. According to Vinay $G$ and Mangalgowri SR, in South Indian population nutrient foramina were located on posterior surface in $87.8 \%$, lateral surface in $8.4 \%$ and along the interosseous border in 3.6\% [5]. The primary factors that affect the position of nutrient foramen are the growth rate at the ends of the shaft and remodeling. Ample knowledge about the position and location of nutrient foramina will help to minimise the length of incision for obtaining the vascularised fibular graft. This in turn will reduce the risk of development of compartment syndrome, a major concern while harvesting the graft.

Direction of the nutrient foramina: In the present study, nutrient foramina were directed distally i.e., away from the growing end in all the right and $96 \%$ of left fibula whereas, in $4 \%$ of the left fibula nutrient foramen was directed proximally i.e., towards the growing end. Sharma MD et al., noticed that of the 153 foramen in 141 fibulae, 131 (85.36\%) were directed distally and 22 (14-63\%) were directed proximally [11]. Mysorekar VR reported that, majority of the fibula had their nutrient foramina pointed away from the growing end in the Indian population [13]. Anomalously directed nutrient foramen of fibula could be explained by the assumption that, it has a peculiar ossification pattern as compared to other long bones of human body. Fibula violates the law of ossification because the secondary centre of ossification for the proximal epiphysis i.e., the growing end appears after the centre of ossification for the distal end. In spite of this marked variation the basic growth pattern of the bone is not altered.

\section{Limitation(s)}

The present study was conducted in limited sample of 50 dry fibulae, because of lack of adequate resources. Variations with respect to gender and age could not be detected, as the bones available for the study were of unknown age and sex.

\section{CONCLUSION(S)}

The distinct morphological characteristics and blood supply of fibula allows the use of vascularised fibular flaps, for the reconstruction of large intercalary bone defects with minimal postoperative complications. Findings in the present study on the distribution, position and direction of the nutrient foramina may prove useful for the surgeons to understand the vascularity of fibula better and to develop methods for harvesting vascularised fibular graft, preserving the nutrient artery.

\section{REFERENCES}

[1] Standring S. Elbow and Forearm In: Gray's anatomy, The Anatomical Basis of Clinical Practice. London: Churchill Livingstone Elsevier; $41^{\text {st }}$ edition, 2016. Pp-1405.

[2] Wei FC, EL-Gammal TA, Lin CH, Ueng WN. Free fibular osteoseptocutaneous graft for reconstruction of segmental femoral shaft defects. J Trauma. 1997;43(5):784-92.

[3] Ojaswini M, Hemang J. Diaphyseal nutrient foramina in long bones and miniature long bones. NJIRM. 2011;2(2):23-26.

[4] Usma R, Nusrat J, Arish NS. Number, direction and location of nutrient foramina of adult fibula and its clinical significance. International Journal of Scientific Research. 2017;6(8):283-85.

[5] Vinay G, Mangalgowri SR. Anatomical study of nutrient foramen of lower limb long bones in south Indian population. Indian Journal of Clinical Anatomy and Physiology. 2017;4(2):222-24

[6] Kaur J, Srivasatava D. Morphometric analysis of fibular graft dimension for placement of dental implant. Journal of the Anatomical Society of India. 2015;64(1):67-72.

[7] Zahid A, Shakir MA, Shireen R. Morphological and topographical anatomy of diaphyseal nutrient foramina of dried Pakistani fibulae. Journal of the College of Physicians and Surgeons Pakistan. 2015;25(8):560-63.

[8] McKee NH, Haw P, Vettese T. Anatomic study of the nutrient foramen in the shaft of the fibula. Clinorthop Relat Res. 1984;184:141-44.

[9] Gumusburun E, Adiguzel E, Eradil H, Ozkan Y, Gulec E. A study of the nutrient foramina in the shaft of the fibula. Okajimas Folia Anat Jpn. 1996;73(2-3):125-27.

[10] Prashanth KU, Murlimanju BV, Prabhu LV, Kumar CG, Pai MM, Dhananjaya KVN Morphological and topographical anatomy of nutrient foramina in the lower limb long bones and its clinical importance Australas Med J. 2011;10:530-37.

[11] Sharma MD, Mathur A, Nagar AK, Barjathia R, Chauhan P, Shekhawat S. Study of morphometric variation in the nutrient foramina of fibula in central Rajasthan. Indian Journal of Clinical Anatomy and Physiology. 2016:3(1):65-71.

[12] Collipal E, Vargas R, Parra X, Silva H, Sol M. Diaphyseal nutrient foramina in the femur, tibia and fibula bones. Int J Morphol. 2007;25(2):305-08.

[13] Mysorekar VR. Diaphyseal nutrient foramina in human long bones. J Anat. 1967;101:813-22.

PARTICULARS OF CONTRIBUTORS:

1. Senior Assistant Professor, Department of Anatomy, Kanyakumari Government Medical College, Nagercoil, Tamil Nadu, India.

2. Senior Assistant Professor, Department of Anatomy, Kanyakumari Government Medical College, Nagercoil, Tamil Nadu, India.

3. Associate Professor, Department of Anatomy, Kanyakumari Government Medical College, Nagercoil, Tamil Nadu, India. Dr. Shoma Alban,

Senior Assistant Professor, Department of Anaotmy, Kanyakumari Government

Medical College, Asaripallam, Nagercoil-629201, Tamil Nadu, India.

E-mail: drshomaalban@gmail.com
NAME, ADDRESS, E-MAIL ID OF THE CORRESPONDING AUTHOR:
PLAGIARISM CHECKING METHODS: [Jain Het al.]

- Plagiarism X-checker: Jan 232021

- Manual Googling: Jun 28, 2021

- iThenticate Software: Aug 03, 2021 (23\%)
ETYMOLOGY: Author Origin

\section{AUTHOR DECLARATION:}

- Financial or Other Competing Interests: None

- Was Ethics Committee Approval obtained for this study? No

- Was informed consent obtained from the subjects involved in the study? No

- For any images presented appropriate consent has been obtained from the subjects.
No
Date of Submission: Jan 22, 2021 Date of Peer Review: Apr 11, 2021 Date of Acceptance: Jul 05, 2021 Date of Publishing: Oct 01, 2021 